\title{
The Central Fragment of Reelin, Generated by Proteolytic Processing In Vivo, Is Critical to Its Function during Cortical Plate Development
}

\author{
Yves Jossin, ${ }^{1}$ Nina Ignatova, ${ }^{1}$ Thomas Hiesberger, ${ }^{2}$ Joachim Herz, ${ }^{2}$ Catherine Lambert de Rouvroit ${ }^{3}$ and \\ André M. Goffinet ${ }^{1}$ \\ ${ }^{1}$ Developmental Genetics Unit, University of Louvain Medical School, B1200 Brussels, Belgium, ${ }^{2}$ Department of Molecular Genetics, University of Texas \\ Southwestern, Dallas, Texas 75390-9046, and ${ }^{3}$ Developmental Neurobiology Unit, Facultés Universitaires Notre-Dame de la Paix Medical School, B5000 \\ Namur, Belgium
}

Reelin is a large extracellular protein that controls cortical development. It binds to lipoprotein receptors very-low-density lipoprotein receptor and apolipoprotein-E receptor type 2, thereby inducing phosphorylation of the adapter Dab1. In vivo, Reelin is cleaved into three fragments, but their respective function is unknown. Here we show the following: (1) the central fragment is necessary and sufficient for receptor binding in vitro and for Dab1 phosphorylation in neuronal cultures; (2) Reelin does not bind the protocadherin cadherin-related neuronal receptor (CNR1) as reported previously; (3) Reelin and its central fragment are equally able to rescue the reeler phenotype in a slice culture assay; and (4) anti-receptor antibodies can induce Dab1 phosphorylation but do not correct the reeler phenotype in slices. These observations show that the function of Reelin is critically dependent on the central fragment generated by processing but primarily independent of interactions with CNR1 and on the N-terminal region. They also indicate that events acting in parallel to Dabl phosphorylation might be required for full activity.

Key words: cortical development; CNR1; Dab1; Reelin; ApoER2; VLDLR

\section{Introduction}

Cortical development proceeds by precursor proliferation in ventricular zones (VZ), followed by neuronal migration to the preplate and cortical plate (CP), and is critically dependent on the function of the Reelin pathway (Lambert de Rouvroit and Goffinet, 1998; Rice and Curran, 2001; Jossin et al., 2003b; Tissir and Goffinet, 2003). Reelin is a glycoprotein of $420-450 \mathrm{kDa}$ that is secreted by several neurons, such as cortical Cajal-Retzius cells. Defective Reelin is the cause of the reeler malformation in mice (D'Arcangelo et al., 1995; Hong et al., 2000) and the NormanRoberts type lissencephaly in man (Hong et al., 2000) (Online Mendelian Inheritance in Man 257320). In reeler mice, neurons are generated in the VZ like in wild-type animals. Although their initial migration is correct, they form abnormal architectonic

Received July 21, 2003; revised 0ct. 14, 2003; accepted 0ct. 20, 2003.

A.M.G. is supported by Fonds de la Recherche Scientifique et Médicale Grant 3.4533.95, Fonds de la Recherche Fondamentale et Collective Grant 2.4504.01, Actions de Recherches Concertées Grants 186 and 248, and the Fondation Médicale Reine Elisabeth, all from Belgium, as well as by the fifth Framework program from the European Union Grant "Concorde" QLG3-CT-2000-00158. J.H. is supported by National Institutes of Health Grants HL20948, NS43408, and HL63762, the Alzheimer Association, the Perot Family Foundation, and the Humboldt Foundation. Y.J. is a fellow from the Fonds de la Recherche pour I'Industrie et I'Agriculture. We thank Tom Curran for gift of the Reelin pCrl construct, Dieter Blaas for the VLDLR-MBP fusion protein, Kasu Nakajima for the Reelin(368-3361) plasmid, Jacques Van Snick for help with monoclonal antibody production, and Christiane Dernoncourt for technical assistance.

Correspondence should be addressed to André M. Goffinet, Developmental Genetics Unit, University of Louvain Medical School, 73 Avenue E, Mounier, Box GEDE 7382, B1200 Brussels, Belgium. E-mail: andre.goffinet@gede.ucl.ac.be.

D0I:10.1523/JNEUROSCI.3408-03.2004

Copyright $\odot 2004$ Society for Neuroscience $\quad 0270-6474 / 04 / 240514-08 \$ 15.00 / 0$ patterns at the end of migration. When normal neurons form a dense, laminar CP in which maturation proceeds from inside to outside, reeler mutant neurons form a loose $\mathrm{CP}$ in which the gradient of maturation is inverted.

Reelin is thought to deliver a signal to migrating neurons, instructing them to assume their correct position. Their response requires binding of Reelin to at least one of two lipoprotein receptors, very-low-density lipoprotein receptor (VLDLR) and apolipoprotein-E receptor type 2 (ApoER2) (Hiesberger et al., 1999; Trommsdorff et al., 1999), but Reelin does not bind to the closely related low-density lipoprotein receptor (LDLR). The signal is relayed by the Dab1 adaptor that interacts with the cytoplasmic tail of receptors (Howell et al., 1997, 1999, 2000; Sheldon et al., 1997; Ware et al., 1997; Bar et al., 2003; Jossin et al., 2003b). Tyrosine phosphorylation of Dab1 after Reelin binding (Howell et al., 2000; Keshvara et al., 2001) is essential: the reeler-like Dab1 $-/-$ phenotype is rescued by a Dabl cDNA encoding key tyrosine residues but not when they are mutated to phenylalanine (Herrick and Cooper, 2002). The Fyn and Src tyrosine kinases are implicated in Dab1 phosphorylation (Arnaud et al., 2003; Bock and Herz, 2003), but Fyn or Src deficiency do not generate a reeler-like phenotype, suggesting redundancy and/or additional complexity in the pathway. That a reeler-like malformation is induced in brain slices incubated with the Src family kinase inhibitor PP2 further demonstrates the implication of these kinases in Reelin signaling (Jossin et al., 2003a). Fyn docks to the cytoplasmic tail of the cadherin-related neuronal receptor-1 (CNR1), 
Table 1. Constructs used in the study

\begin{tabular}{llll}
\hline Name & PCR & Digestion & Amino acids in Reelin \\
\hline Reelin & & Eco47, Notl & 1 to 3461 \\
N-R6 & & 1 to 2712 \\
R3-8 & Yes & 1220 to 3428 \\
R3-6 & Yes & 1220 to 2664 \\
Del3-4-5A & & Agel, Clal & Deletion from 1287 to 2181 \\
N-R5A & & Clal, Notl & 1 to 2181 \\
N-R2 & & Agel, Notl & 1 to 1286 \\
R3-5 & Yes & & 1220 to 2314 \\
R4-6 & Yes & & 1595 to 2664 \\
R3-4 & Yes & & 1220 to 1957 \\
R4-5 & Yes & & 1595 to 2314 \\
R5-6 & Yes & & 1949 to 2664 \\
R7-8 & Yes & 2661 to 3428 \\
R4 & Yes & 1595 to 1957 \\
R6 & Yes & 2314 to 2664 \\
\hline
\end{tabular}

and CNR1 was reported to bind Reelin, thereby recruiting Fyn into the complex (Senzaki et al., 1999). The N-terminal region of Reelin is considered important, because it contains the epitope of the function-blocking CR50 antibody (Ogawa et al., 1995; Miyata et al., 1997; Nakajima et al., 1997). CR50 interferes with Reelin homopolymerization and with Dab1 phosphorylation (Utsunomiya-Tate et al., 2000; Kubo et al., 2002). On the other hand, the N-terminal moiety of Reelin does not bind to receptors (Hiesberger et al., 1999).

Previous work showed that Reelin is cleaved in vivo at two sites located after domains 2 and 6, resulting in the production of three fragments (Lambert de Rouvroit et al., 1999). To understand further the relationship between the different parts of Reelin and its function during development, we studied the binding in vitro of partial Reelin proteins to ectodomains of the VLDLR and ApoER2 receptors and reassessed the binding of Reelin to CNR1; we tested the ability of partial Reelin proteins to elicit Dab1 phosphorylation in neuronal cultures and their capacity to correct the reeler phenotype in embryonic brain slices; and we generated monoclonal antibodies against the extracellular regions of VLDLR and ApoER2 and tested their effects on Dab1 phosphorylation and on reeler slices. Our results indicate that the central fragment of Reelin that contains repeats 3-6 is necessary and sufficient to fulfill most of its functions during cortical development.

\section{Materials and Methods}

Expression of parts of Reelin and other proteins in expression vectors. The Reelin cDNA construct pCrl, kindly provided by Dr. T. Curran (St. Jude's Children's Research Hospital, Memphis, TN) (D’Arcangelo et al., 1997), was used to express Reelin and as a template for PCR amplification. For Reelin constructs, "R" is used for repeat, "N" for N terminus, and "Del" for deletion of a given region. The amplicons for constructs R3-8, R3-6, R3-5, R4-6, R3-4, R4-5, R5-6, R7-8, R4, and R6 (Table 1, Fig. 1) were cloned in the pSecTag2B vector (Invitrogen, San Diego, CA), in-frame with a signal peptide and a C-terminal Myc epitope. Constructs N-R6, Del3-4-5A, N-R5A, and N-R2 were obtained from pCrl by nuclease restriction, followed by ligation. Constructs were verified by sequencing and tested for secretion of the protein by transfection of HEK293T cells. Plasmid pSFRl, kindly provided by K. Nakajima (Keio University, Tokyo, Japan), encodes amino acids 368-3461 of Reelin. This protein (abbreviated $\Delta \mathrm{N}$-Reln) does not contain the G10 and CR50 epitopes (Kubo et al., 2002). The human VLDLR-Fc, human LDLR-Fc, and mouse ApoER2-Fc constructs, tagged with the V5 epitope, were described previously (Hiesberger et al., 1999). Vectors coding for the CNR1 ectodomain, as well as its first ectodomain (EC1) domain, were generated in the same manner as

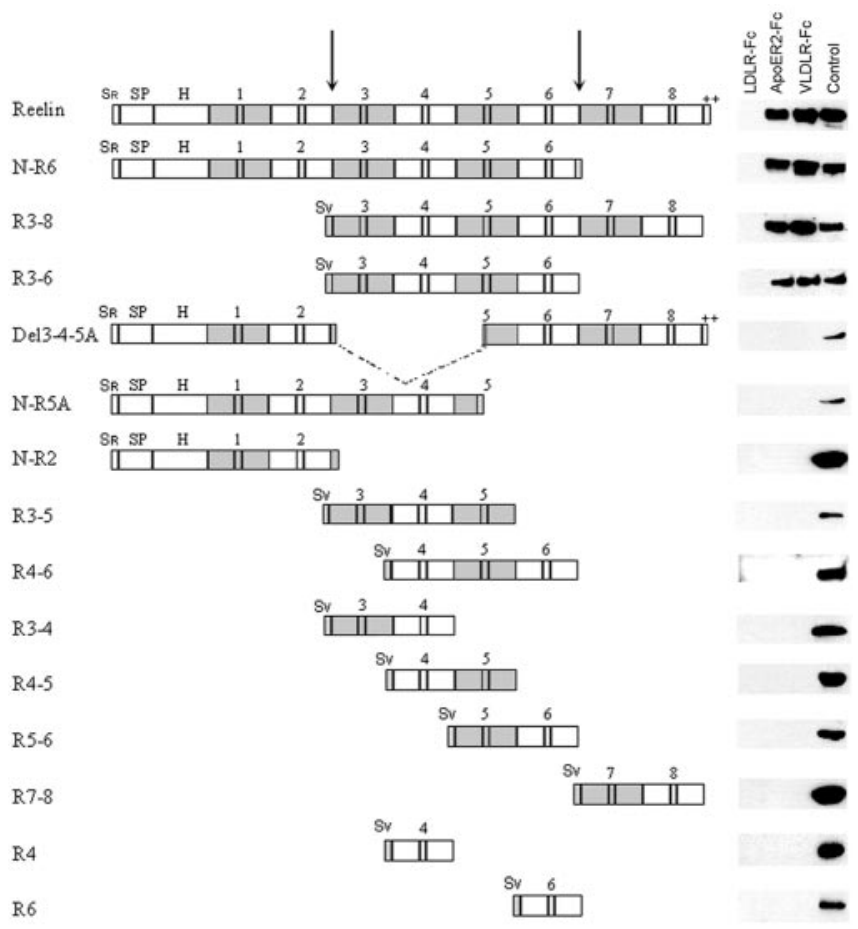

Figure 1. Receptor binding. The different Reelin constructs are shown, together with their ability to coprecipitate with LDLR-Fc, ApoER2-Fc, and VLDLR-Fc. No construct binds to LDLR; only full-length Reelin and proteins N-R6, R3-6, and R3- 8 are able to bind to VLDLR and ApoER2, and they bind similarly to both. The lane labeled Control is a Western blot of supernatant from cells transfected with the different plasmids. Blots were revealed with anti-Reelin $\mathrm{G} 10$ for the constructs that contain region $\mathrm{H}$, with anti-Reelin 12 and 14 for the constructs that contain the C-terminal repeat (de Bergeyck et al., 1998), and with anti-Myc for the others. SR, Sv, Signal peptides of Reelin and encoded by the pSecTag vector; SP; region of Reelin with similarity with F-spondin; $\mathrm{H}$, unique region. Arrows indicate the two Reelin cleavage sites.

lipoprotein receptor constructs, using specific primers and respective full-length cDNAs as template. The CNR1 ectodomain was amplified using the following primers: $5^{\prime}$-ACCATGGAATTTTCCTGGGGAAGTG$3^{\prime}$ and $5^{\prime}$-ATCCACCAGTGACGCCTCAGAGTGTGTG-3'. The EC1 domain was amplified using the following primers: $5^{\prime}$-CCAAGCTTTACCATGGAATTTTCCTGGGGAAG-3' and $5^{\prime}$-AAAGCTTGGGAACCTGGGAGGGTTGTCGTT-3'

Expression of recombinant proteins and pull-down assays. For expression of recombinant Reelin and receptor proteins, HEK293T cells were seeded at $1 \times 10^{6}$ cells per $35 \mathrm{~mm}$ well and transfected $16-20 \mathrm{hr}$ later with $2 \mu \mathrm{g}$ of plasmid DNA using calcium phosphate-DNA precipitation in HEPES, as described previously (Kingston, 2001). They were cultivated in DMEM with $10 \%$ fetal bovine serum (BioWhittaker, Walkersville, $\mathrm{MD}$ ). One day after transfection, the medium was replaced by $1 \mathrm{ml}$ of serum-free medium, which was collected after $24 \mathrm{hr}$, replaced, and collected again after $24 \mathrm{hr}$. Pooled supernatants were used as the source of recombinant protein. The binding of Reelin proteins to lipoprotein receptors was assayed as described previously (Hiesberger et al., 1999) with minor modifications. Briefly, HEK293T cell culture supernatants containing equivalent amount of recombinant LDLR-Fc (in $1 \mathrm{ml}$ ), VLDLR-Fc (in $1 \mathrm{ml}$ ), or ApoER2-Fc (in $2.5 \mathrm{ml}$ ) proteins was mixed with $40 \mu \mathrm{l}$ of protein A-agarose beads (Roche Products, Hertforshire, UK) and incubated overnight at $4^{\circ} \mathrm{C}$ on a rotating wheel. The supernatant was removed, and the beads were incubated with $1 \mathrm{ml}$ of supernatant from HEK293T cells transfected with pCrl or partial Reelin constructs and incubated overnight at $4^{\circ} \mathrm{C}$. Beads were washed successively with radioimmunoprecipitation assay (RIPA) buffer $(0.15 \mathrm{~m} \mathrm{NaCl}, 1 \%$ Triton X-100, $1 \%$ SDS, $0.1 \%$ sodium deoxycholate, $10 \mathrm{~mm}$ sodium phosphate, 2 mм EDTA, and $14 \mathrm{~mm}$ 2-mercaptoethanol), $0.5 \mathrm{~m} \mathrm{NaCl}$, and RIPA. Inclusion of a $0.5 \mathrm{M} \mathrm{NaCl}$ wash was shown to decrease nonspecific binding as evidenced by the absence of binding of Reelin to LDLR-Fc. Proteins 
were eluted from the beads by boiling for $3-5 \mathrm{~min}$ in SDS gel loading buffer, separated by SDS-PAGE (Duracryl, 5\%), and transferred to a polyvinylidene difluoride (PVDF) membrane using a transblot (BioRad, Hercules, CA). Blots were revealed with either anti-Reelin G10 (de Bergeyck et al., 1998) or anti-Myc (9E10; Santa Cruz Biotechnology, Santa Cruz, CA) to reveal, respectively, Reelin or partial Reelin polypeptides or with anti-V5 antibody (Invitrogen) to reveal receptor-Fc constructs. Secondary antibodies were goat anti-mouse antibodies coupled with HRP (Cytomation; Dako, High Wycombe, UK). Chemiluminescent revelation was performed using the Super Signal West Pico kit (Pierce, Rockford, IL). Each fusion protein was tested at least three times.

For estimation of interactions between Reelin and CNR1, recombinant ectodomain-Fc fusion proteins were generated as follows. Briefly, 30 dishes $(60 \mathrm{~mm})$ were transfected with the expression vector, and, $24 \mathrm{hr}$ later, the medium was replaced with medium lacking serum but containing $0.2 \% \mathrm{BSA}$. After another $24 \mathrm{hr}$, culture supernatant was harvested, and the recombinant secreted fusion proteins were purified using protein A-Sepharose as described for VLDLR-Fc (Hiesberger et al., 1999). Recombinant proteins were concentrated $\sim 300$ times, and Western blotting using anti-V5 antibody was performed to evaluate their relative concentration. For pull-down experiments, equal amounts of CNR-Fc proteins were incubated with $30 \mu \mathrm{l}$ of protein A-Sepharose beads, $500 \mu \mathrm{l}$ of BSA buffer (30 mm Tris-Cl, pH 7.4, $130 \mathrm{~mm} \mathrm{NaCl}, 2 \mathrm{~mm} \mathrm{CaCl}$, and $0.2 \% \mathrm{BSA}$ ), and $500 \mu \mathrm{l}$ of supernatant from HEK293 cells transfected with pCrl and incubated for $3 \mathrm{hr}$ at $4^{\circ} \mathrm{C}$. Beads were spun down and washed four times with BSA buffer and once with BSA-free buffer. Bound proteins were analyzed by Western blotting using either anti-V5-HRP conjugate or anti-Reelin-HRP conjugate.

Monoclonal antibodies against VLDLR and ApoER2. The cDNA encoding the extracellular part (amino acids 28-355) of human VLDLR fused to myelin basic protein at its $\mathrm{N}$ terminus and carrying a 6-His tag at the $\mathrm{C}$ terminus, cloned in pMalc2x (New England Biolabs, Beverly, MA), was generously provided by D. Blaas (Institute of Biochemistry, Vienna, Austria). A recombinant protein corresponding to the extracellular part of mouse ApoER2 (amino acids 36-390) carrying a 6-His tag at the $\mathrm{N}$ terminus was cloned in pProex-1 (Invitrogen). Fusion proteins were produced in Escherichia coli, purified on an Ni-NTA agarose column (Qiagen, Hilden, Germany), and used to immunize mice deficient in the corresponding protein (Frykman et al., 1995; Trommsdorff et al., 1999). Monoclonal antibodies were obtained by splenocyte fusion and produced as ascites fluid as described previously (de Bergeyck et al., 1998). Several clones were tested in isolation and in combination, and clones 7G10 (anti-VLDLR) and 2H8 (anti-ApoER2) were selected because they triggered Dab1 phosphorylation in vitro, as explained below.

Primary neuronal cultures and slice cultures. Experiments were performed in accord with national and institutional guidelines for animal care and approved by the competent Animal Ethics Committee. Pregnancies (normal BALB/c mice or homozygous reeler mutant mice on mixed, mainly BALB/c background) were dated by checking for the presence of a vaginal plug; the day of the plug was noted as embryonic day 0.5 (E0.5). Mice were killed by cervical dislocation. Fetuses aged E16.5 were decapitated, and their heads were collected in cold HBSS. Brains were removed under a binocular and kept in cold HBSS, without $\mathrm{Ca}^{2+}$ and $\mathrm{Mg}^{2+}$, supplemented with $0.6 \%$ glucose [calcium and magnesium-free (CMF)-HBSS-G]. The hemispheres were isolated, and ganglionic eminences, olfactory bulbs, and meninges were discarded to leave mostly cerebral cortex. The cortices were incubated in CMF-HBSS-G with $0.1 \%$ trypsin (Invitrogen) for $5 \mathrm{~min}$ at $37^{\circ} \mathrm{C}$. After trituration with a firepolished Pasteur pipette, the cells were washed in CMF-HBSS-G and triturated in $1 \mathrm{ml}$ of DMEM-F-12 (BioWhittaker) containing $0.025 \%$ DNase I and $0.4 \mathrm{mg} / \mathrm{ml}$ soybean trypsin inhibitor (Invitrogen). The suspension was washed with DMEM-F-12, and cells were plated onto 12well plates coated with ECL cell attachment matrix (entactin, collagen IV, and laminin; all from Upstate Biotechnologies, Lake Placid, NY) at a density of $1 \times 10^{6}$ cells per dish, in DMEM-F-12 medium supplemented with $\mathrm{B} 27$ and penicillin-streptomycin (Invitrogen).

For the embryonic slice culture assay, coronal slices from the telencephalon of normal or homozygous reeler embryos (Orleans allele) at E13.5 were cut at a thickness of $300 \mu \mathrm{m}$ with a vibratome and cultivated in Transwell inserts (Costar, Cambridge, MA) in DMEM-F-12 (BioWhittaker) supplemented with B27, G5, and penicillin-streptomycin (Invitrogen). This system allows development of a cortical plate in the slice after $2 \mathrm{~d}$ in vitro (Jossin et al., 2003a). At the end of the culture, slices were fixed in Bouin, embedded in paraffin, cut serially at $8 \mu \mathrm{m}$, and stained with hematoxylin-eosin for histological examination. Recombinant full-length, partial Reelin proteins or anti-receptor antibodies were produced as described above and dialyzed against the slice culture medium for $24 \mathrm{hr}$ before addition to slices in culture. For estimation of preplate splitting, immunochemical staining of chondroitin sulfate was performed with antibody CS-56 (Sigma, St. Louis, MO), or preplate cells were labeled by injection of pregnant dams with bromodeoxyuridine (BrdU) on E10.5.

Dab1 phosphorylation assay. To perform the assay in the presence of equimolar ligand concentrations, the relative concentrations of fulllength Reelin and proteins R3-8, R3-6, N-R5A, N-R6, and Del3-4-5A were adjusted as follows. The concentration of Reelin was estimated using Western blots using antibody 142, by comparison with dilutions of a recombinant protein that contains the 142 epitope (de Bergeyck et al., 1998). Reelin concentrations in supernatants of transfected cells were in the 25-50 pм range; because values of 300-700 pм were used by Howell et al. (1999), supernatants were concentrated approximately eightfold (Biomax columns; Millipore, Bedford, MA) before use. Because construct R3-8 does not contain the 142 epitope, its relative concentration was adjusted to that of Reelin, using antibodies 12 and 14 directed against the C-terminal part of Reelin (de Bergeyck et al., 1998). The relative concentrations of Reelin and $\Delta \mathrm{N}$-Reln were adjusted similarly. Finally, the relative concentrations of R3-6 and R3-8 were adjusted using an anti-Myc antibody. Other constructs were consistently secreted in higher concentrations than Reelin, R3-8, or R3-6.

Primary cortical cell cultures or embryonic slices were rinsed with culture medium and stimulated for $20 \mathrm{~min}$ at $37^{\circ} \mathrm{C}$ with ligand provided as $500 \mu \mathrm{l}$ of concentrated (spin column; Millipore) transfected cell supernatant. Cells were lyzed in an NP-40 buffer (50 mM Tris-HCl, pH 7.5, $150 \mathrm{~mm} \mathrm{NaCl}$, and $1 \%$ Nonidet P-40) supplemented with $50 \mathrm{~mm} \mathrm{NaF}, 2$ $\mathrm{mm} \mathrm{Na}_{3} \mathrm{VO}_{4}, 1 \mathrm{~mm}$ phenylarsine oxide, $2 \mathrm{~mm}$ EDTA, and protease inhibitor mixture (Complete; Roche Products) at $4^{\circ} \mathrm{C}$ for $10 \mathrm{~min}$. Lysates were clarified by centrifugation and incubated overnight at $4^{\circ} \mathrm{C}$ with a rabbit polyclonal antibody raised against a peptide containing the 12 C-terminal amino acids of Dab1, followed by an incubation of $2 \mathrm{hr}$ with protein A-agarose beads (Roche Products). The beads were washed three times with NP-40 buffer, and proteins were eluted by boiling for $5 \mathrm{~min}$ in SDS gel loading buffer and analyzed on an $8 \%$ SDS-PAGE. The proteins were transferred to a PVDF membrane and revealed with a mouse monoclonal anti-Dab1 antibody (E1) or an anti-phosphotyrosine monoclonal antibody (4G10; Upstate Biotechnology).

\section{Results}

\section{The central part of Reelin mediates receptor binding}

Reelin (Fig. 1) starts with a signal peptide of 27 residues that is followed by a region with similarity to F-spondin (amino acids 28-190). A unique segment between amino acids 191 and 500 is followed by eight repeats of $\sim 350$ amino acids (repeat 1 , residues 501-860; repeat 2, 861-1220; repeat 3, 1221-1596; repeat 4, 1597-1947; repeat 5, 1948-2314; repeat 6, 2315-2661; repeat 7, 2662-3051; and repeat 8, 3052-3428). The protein terminates with a basic stretch of 33 amino acids (3429-3461). In vivo, Reelin is processed by cleavage at two sites located, respectively, between repeats 2 and 3 and repeats 6 and 7 (Lambert de Rouvroit et al., 1999) (Fig. 1).

Recombinant full-length Reelin and partial Reelin polypeptides were assayed for binding to the extracellular region of VLDLR and ApoER2, as well as LDLR (negative control), as shown in Figure 1. Binding to LDLR was undetectable for all secreted proteins. Construct N-R2, composed of the spondin similarity region, the unique segment and repeats 1 and 2, thus corresponding to the N-terminal processing fragment, did not 
bind lipoprotein receptors. Even construct N-R5A, which includes the first four Reelin repeats and part of repeat 5, did not bind significantly, confirming that the N-terminal moiety of Reelin is not involved. Similarly, all secreted constructs that contain one, two, or three Reelin repeats, including construct R7-8 that corresponds to the C-terminal processing fragment, failed to bind detectably to VLDLR or ApoER2. In contrast, construct $\mathrm{N}$-R6, which encodes the N-terminal part up to and including repeat 6 , as well as proteins $\mathrm{R} 3-6$, corresponding to the central fragment generated by processing, and R3-8, which contains repeats 3-8, bound to VLDLR and ApoER2 similarly to full-length Reelin. Although detectable binding required at least four repeats, suggesting that binding capacity increased with repeat number, this is not the sole factor. For example, construct Del3$4-5 \mathrm{~A}$, in which repeats 3,4 , and the $\mathrm{N}$-terminal part of repeat 5 are deleted, as well as protein N-R5A did not bind detectably to either receptor, although they contain more than four Reelin repeats. Altogether, the results of these experiments suggested that the central Reelin repeats 3-6, which correspond to the central fragment generated by processing in vivo, are particularly important for receptor binding.

\section{The cadherin-related neuronal receptor CNR1 does not bind Reelin in vitro}

Previous work suggested that the protocadherin CNR1 binds the N-terminal region of Reelin via its EC1 domain (Senzaki et al., 1999). Because Fyn and related kinases are important in Reelin signaling (Arnaud et al., 2003; Bock and Herz, 2003; Jossin et al., 2003a) and CNR1 binds Fyn in its cytoplasmic tail, CNR1 was considered a perfect candidate for a Reelin coreceptor that could bring Fyn in the signaling complex (Senzaki et al., 1999; Yagi, 2001). However, the Reelin-alkaline phosphatase (AP) fusion protein used in this binding study was extracted from cell lysates and not secreted, suggesting that it may not be properly folded. Given the potential importance of that mechanism, we sought to verify the binding in vitro between the whole ectodomain or the EC1 domain of CNR1 and secreted Reelin, as described in Materials and Methods. In contrast to this previous report, we were unable to detect any interaction between the ectodomain or the EC1 region of the CNR1 protein and Reelin, whereas binding of Reelin to lipoprotein receptors was consistently observed in the same conditions (Fig. 2).

\section{The central part of Reelin triggers Dab1 phosphorylation}

The ability of the different Reelin constructs to induce tyrosine phosphorylation of the Dab1 adapter was assessed using primary cortical neuronal cultures. As illustrated in Figure $3 A$, full-length Reelin, N-terminally deleted Reln $(\Delta \mathrm{N}-$ Reln $)$, and proteins R3-8, N-R6, and R3-6 were all able to induce Dab1 phosphorylation, whereas all other Reelin polypeptide constructs were inactive. The addition to native Reelin of proteins N-R2, R3-4, or R5-6 did not modify its capacity to induce Dab1 phosphorylation (data not shown). Some background phosphorylation was observed in the absence of exogenous Reelin or in the presence of small Reelin proteins (Fig. 3A). This background was variable from experiment to experiment. It reflected presumably Reelinindependent phosphorylation, because it was detected even when reeler mutant neurons were used and as tyrosine phosphorylation was assessed using antibody $4 \mathrm{G} 10$, which is not sequence specific. Because the capacity to induce Dab1 phosphorylation probably depends on the concentration of activating ligand, it was important to use similar concentrations to compare the activity of different fusion proteins. Using the normalization described in $\mathrm{Ma}$ -

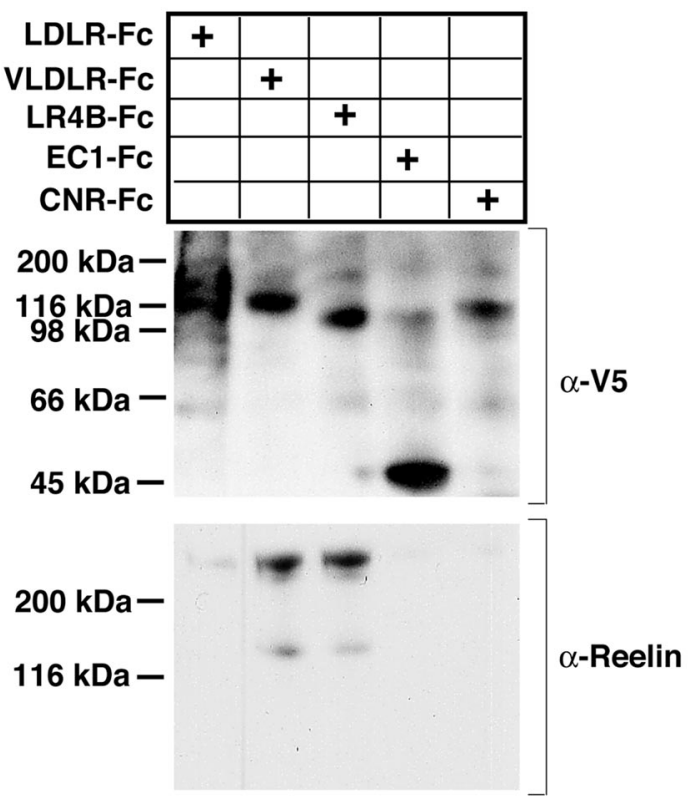

Figure 2. CNR1 does not bind Reelin. Supernatant of transfected HEK293 cells containing full-length, secreted and biologically active Reelin was incubated with the indicated Fc-fusion proteins immobilized on $30 \mu$ l of protein A-Sepharose as described in Materials and Methods. Precipitated proteins were separated by SDS gel electrophoresis and visualized by immunoblotting with the indicated antibodies. Anti-V5 monoclonal antibody equally detects all V5-tagged fusion proteins, irrespective of size. Only ApoER2 and VLDLR, and to a very small degree LDLR, bind Reelin. Neither the full ectodomain (CNR1-Fc) nor the EC1 domain fused to Fc (EC1-Fc) show any detectable Reelin binding under these conditions.

terials and Methods, there was a clear correlation between the ability to bind to receptors and the capacity to stimulate Dab1 phosphorylation. This indicated that R3-6 is sufficient and that no other region is absolutely required to initiate the Dab1dependent branch of Reelin signaling, at least in cells in vitro. In some experiments, full-length Reelin appeared slightly more active in triggering Dabl phosphorylation than the proteins that lacked the N-terminal part, suggesting that this N-terminal region might have an enhancing effect on Dab1 phosphorylation. Reelin preparations contain some proportion of cleavage products, and this proportion increases significantly in the presence of neurons, even during the short $(20 \mathrm{~min})$ incubation time of the assay. To detect a putative interference of the $\mathrm{N}$-terminal sequence, Dab1 phosphorylation assays were performed by using R3-8 alone or in the presence of N-R2. No difference was observed, clearly indicating that the N-terminal fragment did not interfere with the function of the protein.

\section{The central fragment $\mathrm{R} 3-6$ rescues the reeler phenotype in slices}

In brain slices cultivated from E13.5 normal and reeler embryos, the formation of a cortical plate with normal and reeler features, respectively, can be observed after $2 \mathrm{~d}$ in vitro, as shown in Figure $4, A$ and $B$. When slices prepared from reeler embryos were cultivated in the presence of full-length Reelin (Fig. 4C), recombinant Reelin R3-8, composed of the repeats 3-8 (Fig. 4D), or Reelin R3-6, composed of the minimal central region required for receptor binding and Dabl phosphorylation (Fig. 4E), the cortical plate that developed in vitro showed an organization nearly similar to that in normal slices. First, a thin cell-poor marginal zone was visible at subpial level, whereas the marginal zone in reeler slices was barely detectable. Second, the compaction and 
radial orientation of cortical plate cells was better defined than in control reeler slices. Third, immunostaining with the antibody CS56, a preplate marker directed against a chondroitin sulfate proteoglycan epitope, showed that preplate splitting, typically defective in reeler mutant cortex, was partially restored in slices treated with Reelin, R3-8, or R3-6. This was confirmed in rescue experiments performed after labeling of preplate cells by BrdU injection of the pregnant mother on E10.5 (Fig. 5). As a control, no phenotype rescue was observed in reeler slices incubated with the $\mathrm{N}$-terminal region of Reelin (N-R2), which does not bind to receptors and does not trigger Dab1 phosphorylation. As mentioned above, all preparations of Reelin contain a proportion of cleavage products, and this proportion increases during incubation with slices, making it difficult to assess the relative functional potency of native Reelin versus the R3-8 and R3-6 active fragments.

\section{Anti-receptors antibodies stimulate Dab1 phosphorylation but do not correct the reeler phenotype in slices} Different antibodies against the VLDLR and ApoER2 extracellular regions were added to primary neuronal cultures in isolation and in combination, and Dab1 phosphorylation was estimated. Among the combinations tested, two antibodies, 7G10 (against VLDLR) and 2H8 (against ApoER2), were able to increase modestly Dab1 phosphorylation when added separately but triggered a strong phosphorylation when they were added together (Fig. $3 B$ ). This result suggested that, in some conditions, the binding to lipoprotein receptors of ligands unrelated to Reelin is sufficient to initiate the Dab1-dependent component of the Reelin cascade. Interestingly, similar or higher concentrations of stimulating antibodies were unable to correct the reeler trait in slices, although Dab1 phosphorylation was increased (Figs. $4 F$, 6). Dab1 protein levels are increased in reeler mutant brains, and the incubation of reeler slices for $24 \mathrm{hr}$ with active Reelin $\mathrm{R} 3-8$ resulted in a downregulation of Dab1, approximately to the level in normal slices (Fig. 6). However, whereas incubation with stimulating antibodies increased Dab1 phosphorylation as mentioned above, it did not induce a downregulation of Dab1 protein concentrations (Fig. 6). This would suggest that Dab1 phosphorylation alone is not sufficient to transmit the entire Reelin signal.

\section{Discussion}

The present results show that, like full-length Reelin, a partial protein composed of repeats 3-6 is able to bind to VLDLR and
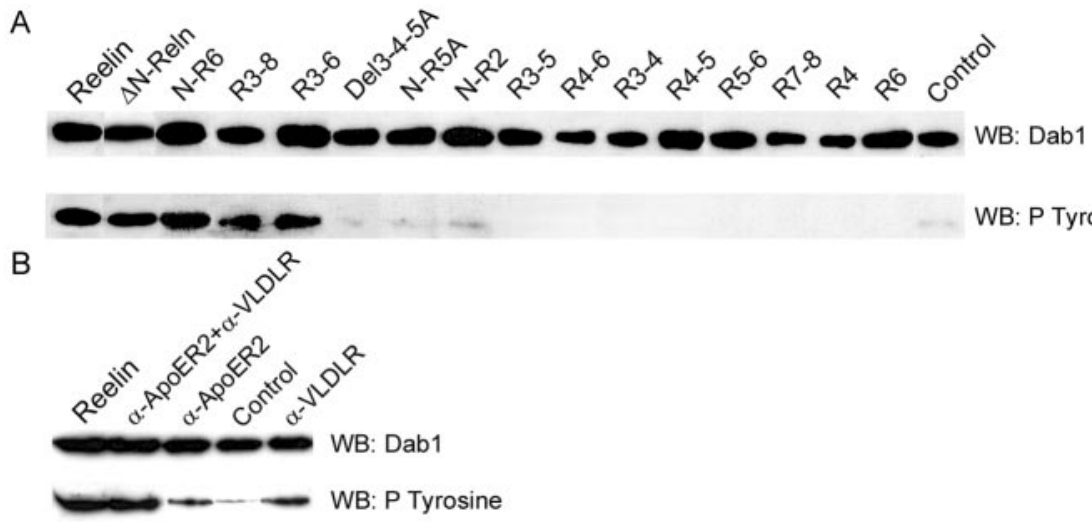

WB: P Tyrosine

Figure 3. Dab1 phosphorylation. A, Stimulation with Reelin proteins. Primary neuronal cultures were treated for 20 min with different full-length and partial Reelin proteins (as supernatant from transfected cells) or with a control supernatant, and Dab1 was immunoprecipitated from the lysate with a rabbit polyclonal antibody against the C-terminal peptide. In the top panel, blots were revealed with a monoclonal anti-Dab1 antibody. In the bottom panel, similar blots were revealed using monoclonal antiphosphotyrosine antibody 4G10. Only full-length $\Delta N$-Reelin and partial N-R6, R3-6, and R3-8 Reelin proteins are able to trigger Dab1 tyrosine phosphorylation. $B$, Stimulation by anti-receptor antibodies. Primary neuronal cultures were treated with monoclonal antibodies, and the levels of Dab1 protein and phosphorylation were assessed as described above. Two antibodies against VLDLR and ApoER2 were found to stimulate Dab1 phosphorylation modestly when added separately but are able to induce phosphorylation to the same extent as full-length Reelin when added together. WB, Western blot.
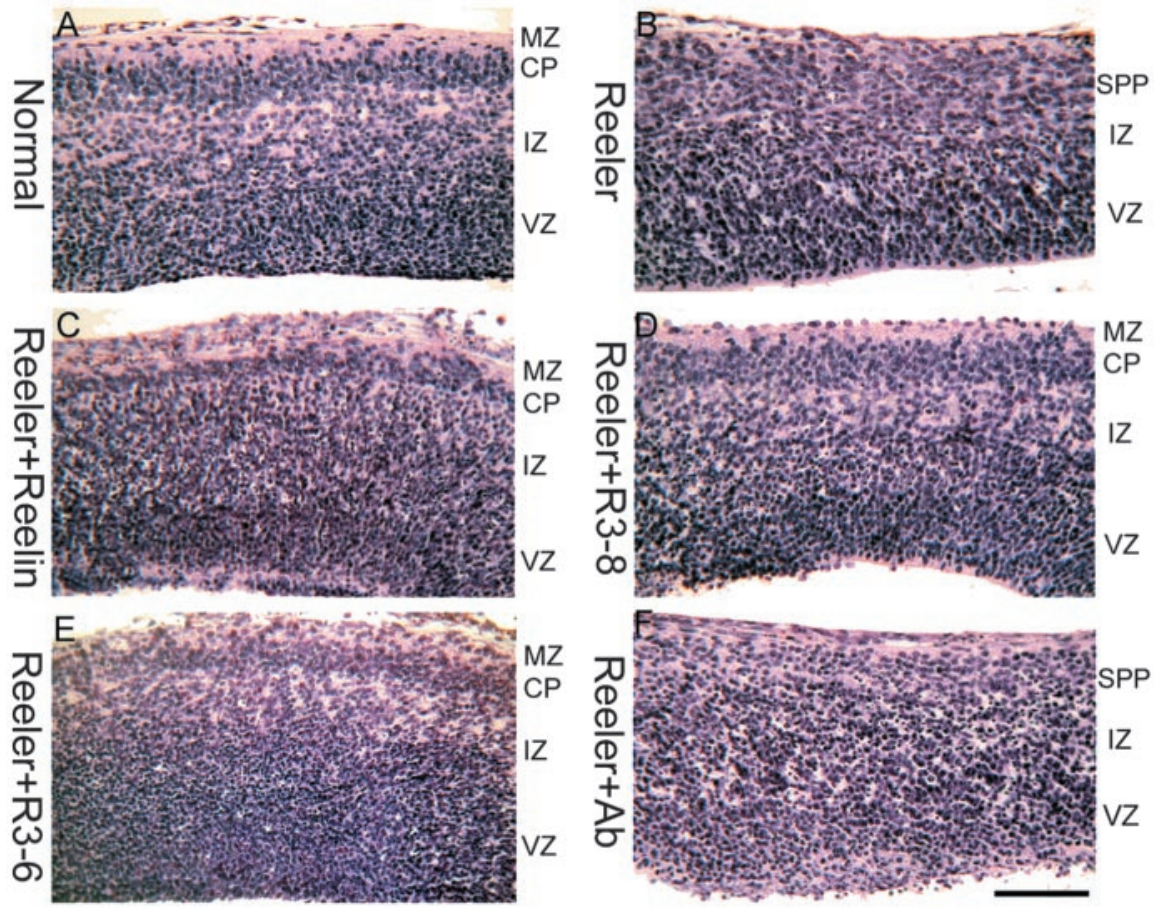

Figure 4. Partial normalization of the reeler phenotype by Reelin, R3-8, and R3-6. Embryonic brain slices were prepared at E13.5, when no $C P$ is present, and cultivated in vitro for $2 \mathrm{~d}$. The $C P$ that develops in vitro from a normal embryo $(A)$ has features of the normal $C P$, including definition of the marginal zone (MZ) and superplate (SPP) and radial neuronal orientation. The (P that develops in a slice from a reeler embryo $(B)$ is disorganized, flanked on its outer aspect by an SPP. A partial normalization of the reeler $C P$ is obtained by addition of full-length $(C), \mathrm{R} 3-8(D)$, and $\mathrm{R} 3-6(E)$ recombinant Reelin but not of the anti-receptor antibody combination that is able to trigger Dab1 phosphorylation ( $F$. Scale bar, $90 \mu \mathrm{m}$. IZ, Intermediate zone; Ab, antibody.
ApoER2 receptors in vitro, to trigger Dab1 tyrosine phosphorylation in neuronal cultures, and to rescue the reeler trait in embryonic brain slices, suggesting that this part of Reelin is functionally critical during cortical plate development. In vivo, Reelin is cleaved at two sites, and comparison with partial Reelin constructs indicated that cleavage proceeds between repeats 2 and 3 and between repeats 6 and 7 (Lambert de Rouvroit et al., 1999; 


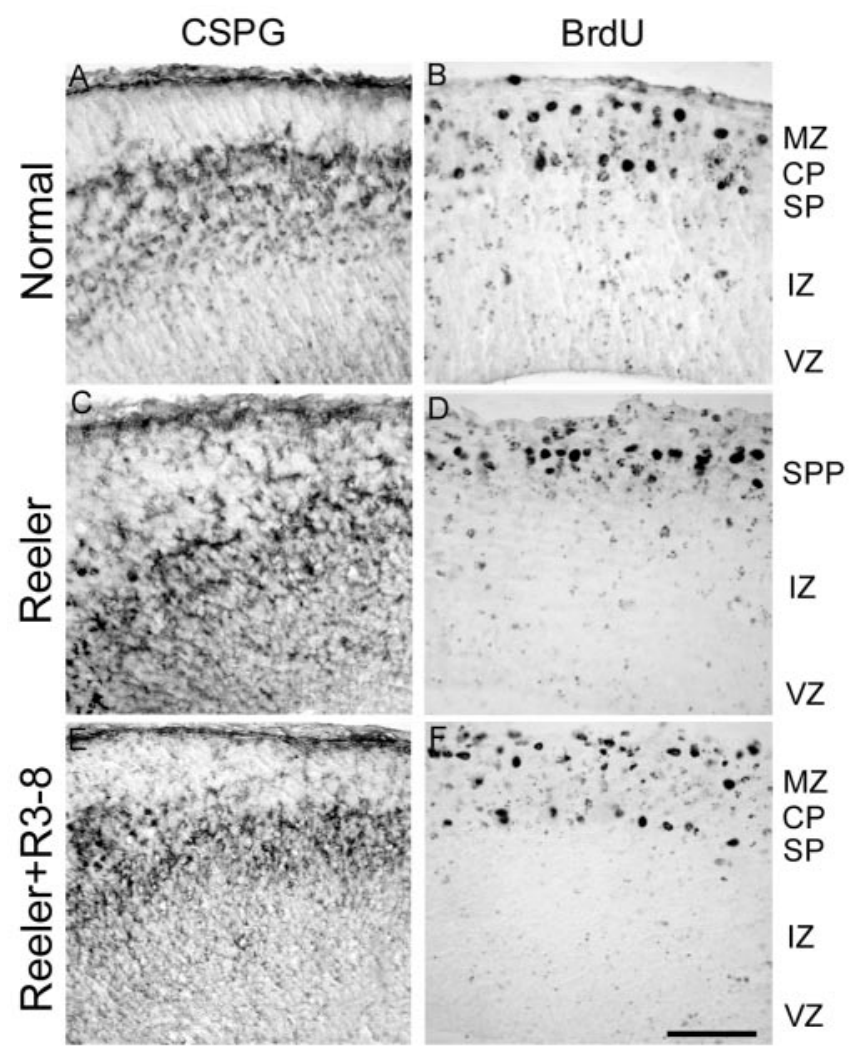

Figure 5. Partial rescue of preplate splitting in reeler slices. Preplate elements were labeled with the anti-chondroitin sulfate antibody CS-56 $(A, C, E)$ or by BrdU injection of the pregnant mother on $E 10.5(B, D, F)$. In normal embryos $(A, B)$, the appearance of the $(P$ results in preplate splitting, with preplate cells located in the marginal zone (MZ) and superplate (SP). In reeler embryos $(C, D)$, no such splitting occurs, and all preplate cells gather in the superplate (SPP). When reeler slices are cultured in the presence of $\mathrm{R} 3-8(E, F), \mathrm{R} 3-6$, or native Reelin (data not shown), a partial splitting of the preplate population is observed. Scale bar, $90 \mu \mathrm{m}$. IZ, Intermediate zone; CSPG, chondroitin sulfate proteoglycan.

Jossin et al., 2003b). Thus, the central fragment produced in vivo corresponds to the functionally active segment defined in this study.

Using our qualitative assay, partial Reelin proteins bind equally to VLDLR and ApoER2, suggesting that homologous regions of receptors are implicated, although native Reelin has a higher affinity for ApoER2 than VLDLR (Andersen et al., 2003). This fits with observations that the phenotypes of VLDLR and ApoER2 null mutant mice are subtle, whereas mice deficient in both genes manifest the reeler-like phenotype, demonstrating a high redundancy (Trommsdorff et al., 1999). Whereas binding of all proteins that contain repeats 3-6 is easily detected, the apparent affinity drops dramatically with all other constructs, indicating that the number of repeats is important. Moreover, this is not the sole factor, and the absence of binding of some proteins with up to five repeats clearly demonstrates qualitative differences. We observed a close correlation between binding to receptors and stimulation of Dab1 tyrosine phosphorylation, suggesting that the same central segment of Reelin is critically important for both events.

The stimulation of Dab1 phosphorylation elicited by monoclonal anti-VLDLR and ApoER2 receptor antibodies indicates that the dimerization of these receptors may be sufficient to trigger the Dab1-dependent part of the signal. On the other hand, two candidate Reelin coreceptors have been proposed previously, namely $\alpha-3 \beta-1$ integrins (Dulabon et al., 2000) and protocad-
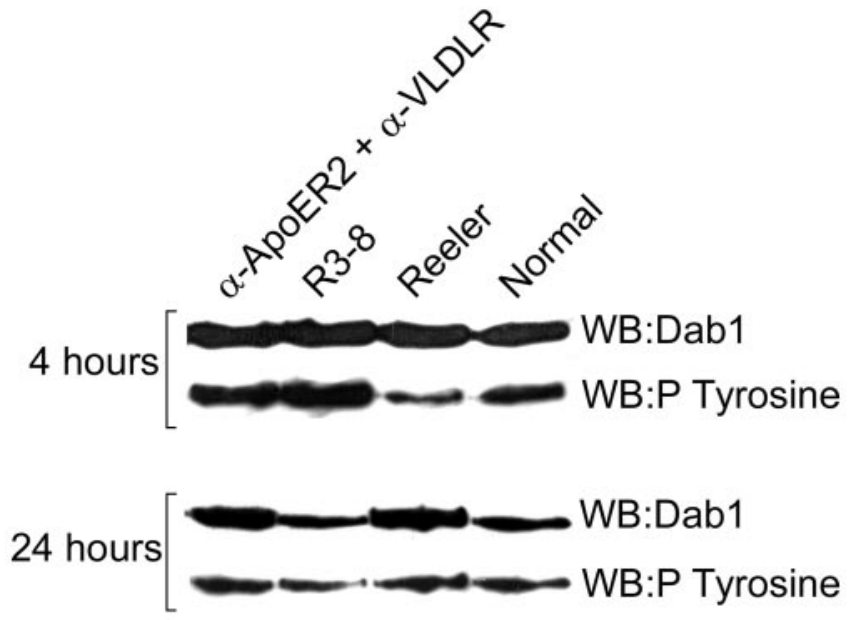

Figure 6. Dab1 phosphorylation and protein levels in slices. reeler slices were cultured in control conditions, in the presence of active R3-8 or stimulating antibodies and compared with normal slices. Dab1 phosphorylation and protein levels were estimated after 4 and $24 \mathrm{hr}$ in vitro. After $4 \mathrm{hr}$, both the antibodies and R3-8 induced a phosphorylation of Dab1 that was comparable with that in normal slices. After $24 \mathrm{hr}, \mathrm{R3}-8$ resulted in a downregulation of Dab1 protein levels that, however, failed to occur in slices treated with antibodies.

herins of the CNR family (Senzaki et al., 1999). The phenotypes of mice deficient in $\beta 1$ integrins are distinctively different from reeler (Graus-Porta et al., 2001; Magdaleno and Curran, 2001). Nevertheless, the increase in the amount of the N-terminal fragment of Reelin in $\alpha-3$ integrin-deficient brains compared with brains from control mice (Dulabon et al., 2000) suggests a functional link between integrins and Reelin that should be studied further. It has been suggested that the protocadherin CNR1 binds extracellularly to the $\mathrm{N}$-terminal region of Reelin. This molecule also binds the Fyn tyrosine kinase at its C-terminal tail and could thereby participate in Dab1 phosphorylation (Senzaki et al., 1999). However, although this mechanism is appealing and generated wide interest, our present observations fail to confirm significant interactions between Reelin and CNR1. A likely explanation for these divergent results lies in the reagents that were used to examine this possible interaction. The secreted CNR1 ectodomain fusion proteins were identical in both studies. However, whereas we used full-length, secreted and biologically active Reelin, Senzaki et al. (1999) used a Reelin-AP fusion construct that failed to be secreted from transfected cells and instead had to be released, presumably from an aggregated state in the endoplasmic reticulum, by detergent solubilization. The finding that misfolded Reelin-AP fusion proteins might bind CNR1-Fc nonspecifically is supported by our unpublished observations that a presumably incompletely folded LDLR-Fc fusion protein obtained from transfected cell lysates interacts with Reelin in vitro, whereas the same protein, harvested from the culture medium, does not. Thus, the present results make a physiological role of CNRs as Reelin coreceptor less likely.

Like the full-length protein, Reelin fragments containing repeats 3-8 and 3-6 are able to stimulate Dab1 phosphorylation and to rescue the reeler cortical plate phenotype in a slice assay, suggesting that the central region containing repeats 3-6 is sufficient to fulfill the functions of Reelin during cortical plate development. The observation that most biological functions of Reelin are recapitulated by its central fragment show that the cleavage that occurs in vivo does not inactivate the protein. Because all preparations of native Reelin contain processing fragments and their proportion increases during incubation with 
slices, it is not presently possible to assess the relative activity of full-length and fragments of Reelin. In explant cultures, Reelin processing was best inhibited by zinc chelators such as o-phenanthroline (Lambert de Rouvroit et al., 1999), which proved, however, too toxic to be used in our slice culture assay. Although the correction of the reeler phenotype in slices presumably does not mimic faithfully the in vivo situation, the effect obtained is comparable with the partial rescue observed in transgenic mice that express the reelin cDNA under control of the nestin promoter (Magdaleno et al., 2002). The observation that the addition of exogenous Reelin to reeler slices is able to correct their phenotype suggests that Reelin does not need to be produced locally in the marginal zone to fulfill its role. In the transgenic experiments mentioned above (Magdaleno et al., 2002), ectopic Reelin expression in ventricular zones similarly resulted in significant phenotype rescue. This suggests that Reelin could put neurons in a permissive state to respond to another signal in the marginal zone rather than provide a direct instruction such as a stop (Tissir and Goffinet, 2003).

Unlike Reelin or R3-8, the same anti-receptor antibodies that are able to stimulate Dab1 phosphorylation do not have correcting activity in slices and do not induce the downregulation of Dabl protein concentration. Thus far, the relative kinetics of Dab1 phosphorylation under Reelin or antibody stimulation could not be compared, and the identity of phosphorylated tyrosine residues in both conditions remains to be defined. With those reservations, our results indicate that integration of the Reelin signal might require more than Dab1 phosphorylation and confirm a previous report that the Reelin-induced decrease of Dab1 protein level is partly independent of Dab1 tyrosine phosphorylation (Howell et al., 2000).

Our results can best be explained by postulating the need for Reelin-dependent recruitment of other cell surface molecules, possibly the integrins (Dulabon et al., 2000; Rodriguez et al., 2000), but probably not CNR1, into the complex. Although these recruited components of the Reelin signaling complex would obviously not be required for induction of Dab1 phosphorylation, these membrane proteins or associated cytoplasmic factors might be themselves substrates for the intracellular kinases that are stimulated by Reelin-binding to ApoER2 and VLDLR. It is possible that, for instance, phosphorylation of these biological effector molecules by Reelin-activated kinases could regulate neuronal migration and positioning by modulating cell adhesion. Alternatively, a Dab1-independent action of Reelin could be provided by its reported intrinsic serine proteinase activity that is able to modulate synaptic maturation (Quattrocchi et al., 2003). Thus far, however, the part of Reelin implicated in this activity is not fully defined.

The N-terminal region of Reelin is not absolutely required for activity, at least in the in vitro and ex vivo assays that we used. Other work pointed to the importance of the N-terminal moiety that contains the epitope of the monoclonal antibody CR50 (Ogawa et al., 1995), which was reported to have function blocking activity (Miyata et al., 1997; Nakajima et al., 1997). The $\mathrm{N}$-terminal region of Reelin mediates aggregation, and the formation of homopolymers increases the ability of Reelin to stimulate Dab1 phosphorylation. Both homopolymer formation and Dab1 phosphorylation were decreased by CR50 (UtsunomiyaTate et al., 2000; Kubo et al., 2002). Our results show that fulllength Reelin is indeed slightly more efficient than partial proteins in the Dab1 phosphorylation assay. As a result of the use of transfected cell supernatants and neuronal or slice cultures, the assays that are presently available cannot be quantified using pu- rified components. In vivo, homopolymer formation could increase the effective Reelin concentration and allow the recruitment of more receptor units, thereby increasing signal activation.

In conclusion, our results show that Reelin binds to lipoprotein receptors via its central region that corresponds to the middle fragment generated by processing. This could organize a supramolecular complex at the plasma membrane and/or modulate endocytosis and intracellular traffic of signaling molecules. Other components could be recruited by binding to Reelin directly ("coreceptors") or by cis interactions with lipoprotein receptors and/or Dab1. By analogy with the role of lipoprotein receptorrelated protein (LRP) as a coreceptor of PDGF signaling (Boucher et al., 2002; Loukinova et al., 2002) and the implication of LRP6 as a mediator of Wnt signaling (Pinson et al., 2000), it is tempting to speculate that Reelin, VLDLR, ApoER2, Dab1, and cytoplasmic kinases such as Fyn may work in parallel with another system that remains to be identified.

\section{References}

Andersen OM, Benhayon D, Curran T, Willnow TE (2003) Differential binding of ligands to the apolipoprotein e receptor 2. Biochemistry 42:9355-9364.

Arnaud L, Ballif BA, Forster E, Cooper JA (2003) Fyn tyrosine kinase is a critical regulator of disabled-1 during brain development. Curr Biol 13:9-17.

Bar I, Tissir F, Lambert De Rouvroit C, De Backer O, Goffinet AM (2003) The gene encoding disabled-1 (DAB1), the intracellular adaptor of the Reelin pathway, reveals unusual complexity in human and mouse. J Biol Chem 278:5802-5812.

Bock HH, Herz J (2003) Reelin activates SRC family tyrosine kinases in neurons. Curr Biol 13:18-26.

Boucher P, Liu P, Gotthardt M, Hiesberger T, Anderson RG, Herz J (2002) Platelet-derived growth factor mediates tyrosine phosphorylation of the cytoplasmic domain of the low density lipoprotein receptor-related protein in caveolae. J Biol Chem 277:15507-15513.

D’Arcangelo G, Miao GG, Chen SC, Soares HD, Morgan JI, Curran T (1995) A protein related to extracellular matrix proteins deleted in the mouse mutant reeler. Nature 374:719-723.

D’Arcangelo G, Nakajima K, Miyata T, Ogawa M, Mikoshiba K, Curran T (1997) Reelin is a secreted glycoprotein recognized by the CR-50 monoclonal antibody. J Neurosci 17:23-31.

de Bergeyck V, Naerhuyzen B, Goffinet AM, Lambert de Rouvroit C (1998) A panel of monoclonal antibodies against Reelin, the extracellular matrix protein defective in reeler mutant mice. J Neurosci Methods 82:17-24.

Dulabon L, Olson EC, Taglienti MG, Eisenhuth S, McGrath B, Walsh CA, Kreidberg JA, Anton ES (2000) Reelin binds alpha3betal integrin and inhibits neuronal migration. Neuron 27:33-44.

Frykman PK, Brown MS, Yamamoto T, Goldstein JL, Herz J (1995) Normal plasma lipoproteins and fertility in gene-targeted mice homozygous for a disruption in the gene encoding very low density lipoprotein receptor. Proc Natl Acad Sci USA 92:8453-8457.

Graus-Porta D, Blaess S, Senften M, Littlewood-Evans A, Damsky C, Huang Z, Orban P, Klein R, Schittny JC, Muller U (2001) Betal-class integrins regulate the development of laminae and folia in the cerebral and cerebellar cortex. Neuron 31:367-379.

Herrick TM, Cooper JA (2002) A hypomorphic allele of dab1 reveals regional differences in Reelin-Dabl signaling during brain development. Development 129:787-796.

Hiesberger T, Trommsdorff M, Howell BW, Goffinet A, Mumby MC, Cooper JA, Herz J (1999) Direct binding of Reelin to VLDL receptor and ApoE receptor 2 induces tyrosine phosphorylation of disabled-1 and modulates tau phosphorylation. Neuron 24:481-489.

Hong SE, Shugart YY, Huang DT, Shahwan SA, Grant PE, Hourihane JO, Martin ND, Walsh CA (2000) Autosomal recessive lissencephaly with cerebellar hypoplasia is associated with human RELN mutations. Nat Genet 26:93-96.

Howell BW, Hawkes R, Soriano P, Cooper JA (1997) Neuronal position in the developing brain is regulated by mouse disabled-1. Nature 389:733-737.

Howell BW, Herrick TM, Cooper JA (1999) Reelin-induced tryosine phos- 
phorylation of disabled 1 during neuronal positioning. Genes Dev 13:643-648.

Howell BW, Herrick TM, Hildebrand JD, Zhang Y, Cooper JA (2000) Dab1 tyrosine phosphorylation sites relay positional signals during mouse brain development. Curr Biol 10:877-885.

Jossin Y, Ogawa M, Métin C, Tissir F, Goffinet AM (2003a) Inhibition of Src family kinases and non-classical protein kinases $\mathrm{C}$ induce a reeler-like malformation of cortical plate development. J Neurosci 23:9953-9959.

Jossin Y, Bar I, Ignatova N, Tissir F, De Rouvroit CL, Goffinet AM (2003b) The Reelin signaling pathway: some recent developments. Cereb Cortex 13:627-633.

Keshvara L, Benhayon D, Magdaleno S, Curran T (2001) Identification of Reelin-induced sites of tyrosyl phosphorylation on disabled 1. J Biol Chem 276:16008-16014.

Kingston RE (2001) Transfection of DNA into eukaryotic cells. In: Current protocols in molecular biology (Ausubel FM, ed), pp 9.1.1-9.1.11. New York: Wiley.

Kubo K, Mikoshiba K, Nakajima K (2002) Secreted Reelin molecules form homodimers. Neurosci Res 43:381-388.

Lambert de Rouvroit C, Goffinet AM (1998) The reeler mouse as a model of brain development. Adv Anat Embryol Cell Biol 150:1-106.

Lambert de Rouvroit C, de Bergeyck V, Cortvrindt C, Bar I, Eeckhout Y, Goffinet AM (1999) Reelin, the extracellular matrix protein deficient in reeler mutant mice, is processed by a metalloproteinase. Exp Neurol $156: 214-217$.

Loukinova E, Ranganathan S, Kuznetsov S, Gorlatova N, Migliorini MM, Loukinov D, Ulery PG, Mikhailenko I, Lawrence DA, Strickland DK (2002) Platelet-derived growth factor (PDGF)-induced tyrosine phosphorylation of the low density lipoprotein receptor-related protein (LRP). Evidence for integrated co-receptor function between LRP and the PDGF. J Biol Chem 277:15499-15506.

Magdaleno SM, Curran T (2001) Brain development: integrins and the Reelin pathway. Curr Biol 11:R1032-R1035.

Magdaleno S, Keshvara L, Curran T (2002) Rescue of ataxia and preplate splitting by ectopic expression of Reelin in reeler mice. Neuron 33:573-586.

Miyata T, Nakajima K, Mikoshiba K, Ogawa M (1997) Regulation of Purkinje cell alignment by Reelin as revealed with CR-50 antibody. J Neurosci 17:3599-3609.

Nakajima K, Mikoshiba K, Miyata T, Kudo C, Ogawa M (1997) Disruption of hippocampal development in vivo by CR-50 mAb against Reelin. Proc Natl Acad Sci USA 94:8196-8201.

Ogawa M, Miyata T, Nakajima K, Yagyu K, Seike M, Ikenaka K, Yamamoto H, Mikoshiba K (1995) The reeler gene-associated antigen on CajalRetzius neurons is a crucial molecule for laminar organization of cortical neurons. Neuron 14:899-912.

Pinson KI, Brennan J, Monkley S, Avery BJ, Skarnes WC (2000) An LDLreceptor-related protein mediates Wnt signalling in mice. Nature 407:535-538.

Quattrocchi CC, Huang C, Niu S, Sheldon M, Benhayon D, Cartwright Jr J, Mosier DR, Keller F, D'Arcangelo G (2003) Reelin promotes peripheral synapse elimination and maturation. Science 301:649-653.

Rice DS, Curran T (2001) Role of the Reelin signaling pathway in central nervous system development. Annu Rev Neurosci 24:1005-1039.

Rodriguez MA, Pesold C, Liu WS, Kriho V, Guidotti A, Pappas GD, Costa E (2000) Colocalization of integrin receptors and Reelin in dendritic spine postsynaptic densities of adult nonhuman primate cortex. Proc Natl Acad Sci USA 97:3550-3555.

Senzaki K, Ogawa M, Yagi T (1999) Proteins of the CNR family are multiple receptors for Reelin. Cell 99:635-647.

Sheldon M, Rice DS, D’Arcangelo G, Yoneshima H, Nakajima K, Mikoshiba K, Howell BW, Cooper JA, Goldowitz D, Curran T (1997) Scrambler and yotari disrupt the disabled gene and produce a reeler-like phenotype in mice. Nature 389:730-733.

Tissir F, Goffinet AM (2003) Reelin and brain development. Nat Rev Neurosci 4:496-505.

Trommsdorff M, Gotthardt M, Hiesberger T, Shelton J, Stockinger W, Nimpf J, Hammer RE, Richardson JA, Herz J (1999) Reeler/Disabled-like disruption of neuronal migration in knockout mice lacking the VLDL receptor and ApoE receptor 2. Cell 97:689-701.

Utsunomiya-Tate N, Kubo K, Tate S, Kainosho M, Katayama E, Nakajima K, Mikoshiba K (2000) Reelin molecules assemble together to form a large protein complex, which is inhibited by the function-blocking CR-50 antibody. Proc Natl Acad Sci USA 97:9729-9734.

Ware ML, Fox JW, Gonzalez JL, Davis NM, Lambert de Rouvroit C, Russo CJ, Chua SC Jr, Goffinet AM, Walsh CA (1997) Aberrant splicing of a mouse disabled homolog, mdab1, in the scrambler mouse. Neuron 19:239-249.

Yagi T (2001) Signalling cascade of CNR cadherins (Reelin receptors) in the mammalian brain. Symp Soc Exp Biol 53:51-57. 